\title{
Poda e sistemas de condução na produção de figos verdes
}

\author{
Carlos Antonio Alvarenga Gonçalves ${ }^{(1)}$, Luiz Carlos de Oliveira Lima( ${ }^{(2)}$, Paulo Sérgio Nascimento Lopes ${ }^{(3)}$ \\ e Magalhães Teixeira de Souza(4)
}

\begin{abstract}
(1)Centro Federal de Educação Tecnológica de Uberaba, Rod. BR 050, Km 499, Antiga Estrada das Mangabeiras, Zona Rural, CEP 38045-000, Uberaba, MG, E-mail: caeafsal@hotmail.com (2)Universidade Federal de Lavras, Dep. de Ciência dos Alimentos, Caixa Postal 3037, CEP 37200-000 Lavras, MG. (3)Universidade Federal de Minas Gerais, Dep. de Agricultura, Núcleo de Ciências Agrárias, Av. Osmane Barbosa, s/noo, Caixa Postal 135, CEP 39404-006 Montes Claros, MG. (4)Escola Agrotécnica Federal de Salinas, Rod. Salinas/Taiobeiras, BR 251, Km 2, Fazenda Varginha, CEP 39560-000 Zona Rural Salinas, MG.
\end{abstract}

Resumo - O objetivo deste trabalho foi verificar o efeito da época de poda e de sistemas de condução sobre crescimento, produção e qualidade de frutos da figueira cultivada na região norte mineira, sob irrigação. O delineamento utilizado foi em blocos ao acaso, com quatro repetições, e os tratamentos arranjados em esquema fatorial 4x2, tomando por fatores épocas de poda (junho, setembro, dezembro e março) e sistemas de condução (com desponte e sem desponte). Em cada parcela, constituída de três plantas úteis, foram coletados dados nos ciclos de produção 2000/2001 e 2001/2002. Não houve interação entre os fatores época de poda e sistema de condução. Houve diferenças de produção entre épocas de poda; plantas podadas em março e junho apresentaram maiores produções. Não houve diferença de produção entre os dois sistemas de condução. Diferentes épocas de poda e sistemas de condução não influíram na qualidade dos frutos em relação a teores de sólidos solúveis totais, $\mathrm{pH}$, acidez total titulável, açúcares totais, glucose, sacarose e amido. A poda da figueira em diferentes épocas do ano pode propiciar produção na entressafra da cultura no norte de Minas Gerais, sem alterar a qualidade dos frutos verdes com padrão para a indústria.

Termos para indexação: Ficus carica, crescimento de frutos, qualidade de frutos.

\section{Pruning and conduction system in the yield of green fig}

\begin{abstract}
The objective of the work was to verify the effect of pruning time and conduction system on growth, yield, and quality of the fig tree fruit grown in the northern Minas Gerais region, under irrigation. The design utilized was randomized blocks with four replicates, and the treatments arranged in a $4 \times 2$ factorial scheme, taking as factors pruning times (June, September, December and March) and conduction system (with lopping and without lopping). In each plot, made up of three useful plants, data concerning the cropping cycles of 2000/2001 and 2001/2002 were collected. No interaction between the factors pruning time and conduction system was verified. There were yield differences between pruning times; the March- and June-pruned plants presented higher yields. There were no yield differences between the conduction systems. Different pruning times and conduction systems did not affect quality of fig tree fruit and contents of total soluble solids, $\mathrm{pH}$, total titrable acidity, total sugars, glucose, sucrose and starch.
\end{abstract}

Index terms: Ficus carica, fruit growth, fruit quality.

\section{Introdução}

A figueira (Ficus carica L.), da família das moráceas, é originária da Ásia Menor e da Síria, de onde se dispersou pelos países da Bacia Mediterrânea (Nogueira, 1995).

No Brasil, a variedade Roxo de Valinhos, que pertence ao tipo comum, é a única cultivada comercialmente. Sua produção pode ser destinada à indústria, para fabricação de produtos com alto valor nutritivo, como purês, geléias e doces, ou para o consumo in natura (Pedrotti, 1982).

Planta rústica, a figueira possui ampla adaptação climática; há relatos de produções significativas em regiões temperadas, como no Rio Grande do Sul, e em regiões áridas tropicais, como no Município de Juazeiro, BA(Albuquerque \& Albuquerque, 1981). A região semiárida com irrigação é favorável ao cultivo da figueira, tendo em vista que a frutificação ocorre de forma 
escalonada, em talhões diferentes, o ano inteiro, produzindo frutos na entressafra (Resende et al., 1994).

A poda de inverno ou de frutificação da figueira, no Brasil, normalmente ocorre nos meses de julho e agosto. A produção é obtida nos ramos novos, ou do ano, emitidos no mesmo ciclo. Assim, promove-se a eliminação quase total da copa formada no ciclo anterior, quando os ramos são reduzidos a 5-10 cm, de forma a ficarem com pelo menos duas gemas em suas extremidades, voltadas para fora da planta, para a formação da nova copa (Chalfun et al., 1998).

Em novembro começa a colheita do figo verde, estendendo-se até maio do ano subseqüente, com maior concentração da safra de fevereiro a abril, nas condições do sul e sudoeste de Minas Gerais (Abrahão et al., 1997).

Para obter produção de frutos na entressafra, em regiões tradicionais produtoras de figo, os fruticultores têm antecipado a execução da poda, com objetivo de adiantar o ciclo de crescimento e a época de colheita. Porém, nessas regiões, existe um sério inconveniente em praticar a poda antecipada, uma vez que figueiras em brotação são bastante susceptíveis à queima pelas geadas, que costumam ocorrer nessa época (Rigitano, 1964). Ao contrário, em regiões de inverno ameno e livre de geadas, as podas antecipadas apresentam bons resultados de produção (Santos et al., 2001).

Embora o figo seja comercializado em larga faixa do ano, entre junho e novembro a oferta ainda é mínima ou mesmo inexistente. Dessa forma, o estudo de diferentes épocas de poda e sistemas de condução da figueira e das características de qualidade da fruta torna-se fundamental para o avanço da cultura em regiões quentes de inverno ameno, como no norte de Minas Gerais, podendo proporcionar safras extemporâneas com frutos de alta qualidade, tornando-se boa opção de renda.

Este trabalho objetivou avaliar o efeito de épocas de poda e sistemas de condução no desenvolvimento, produção e qualidade da fruta verde da figueira cultivada na região norte-mineira.

\section{Material e Métodos}

O trabalho foi desenvolvido na Unidade Demonstrativa de Produção Frutícola da Escola Agrotécnica Federal de Salinas, de abril de 1999 a dezembro de 2002, no Município de Salinas, norte de Minas Gerais. O clima da região é classificado como Aw; a localização geográfica é $16^{\circ} 10^{\prime}$ e $42^{\circ} 17^{\prime}$ e 427 m de altitude.
O clima apresenta temperatura média anual de $25^{\circ} \mathrm{C}$, umidade relativa média de $65 \%$, precipitação pluvial total anual de 700 a $1.200 \mathrm{~mm}$, concentrando o período chuvoso de outubro a abril, e insolação média anual em torno de 1.980 horas. O solo é do tipo Latossolo Vermelho-Amarelo, com textura areno-argilosa.

O delineamento utilizado foi o de blocos ao acaso, com três repetições, e os tratamentos foram arranjados em esquema fatorial $4 \times 2$, tomando por fatores épocas de poda (março, junho, setembro, dezembro) e sistema de condução com desponte e sem desponte. Cada parcela apresentava cinco plantas, das quais somente as três centrais foram consideradas úteis.

O sistema de condução com desponte consistiu em despontar os ramos produtivos quando atingiram 16 folhas ou o oitavo par de folha e, a partir daí, conduziram-se dois brotos que saíram da ponta do ramo, sendo realizado o desponte desses dois ramos quando atingiram o terceiro par de folhas. Esse processo de desponte, no terceiro par de folhas e condução de dois ramos, foi repetido, até a época de se podar novamente, por aproximadamente seis vezes. Já o sistema de condução sem desponte consistiu em conduzir os ramos produtivos em haste única, apenas com desbrotas laterais, sem o uso do desponte.

O experimento foi instalado utilizando-se mudas obtidas de estacas lisas, adquiridas em dezembro de 1997 na fazenda da Escola Agrotécnica Federal de Salinas, norte de Minas Gerais. As estacas foram colocadas para enraizar em saco de plástico contendo, como substrato, uma mistura de $50 \%$ de terra e $50 \%$ de areia. A variedade utilizada foi a Roxo de Valinhos.

As mudas foram transplantadas em março de 1998 para covas, com dimensões de 40x40x40 cm, num espaçamento 2,5x1,5 m, recomendado para a produção de figos verdes (Almeida \& Silveira, 1997). Utilizou-se sistema de irrigação por microaspersão, e os tratos culturais e fitossanitários foram realizados conforme as recomendações de Almeida \& Silveira (1997).

As mudas foram plantadas em março de 1999 e conduzidas em haste única até a altura de $50 \mathrm{~cm}$. A partir desta altura, aproximadamente três meses depois do plantio, efetuou-se a poda de ramificação para forçar as brotações laterais e, quando essas ramificações laterais atingiram $10 \mathrm{~cm}$, foram selecionados três ramos mais vigorosos (pernadas) e bem distribuídos, de forma a manterem entre si um ângulo de 120 graus, sendo os demais eliminados. Esses brotos formaram a base da copa da planta, a uma altura de 30 a $50 \mathrm{~cm}$ do solo. 
Um ano depois do plantio, foram aplicados os tratamentos às plantas, iniciando a primeira época de poda e o sistema de condução com desponte e sem desponte. A poda no primeiro ciclo (2000/2001) consistiu no encurtamento dos três ramos com um tamanho de 5 a $8 \mathrm{~cm}$ de comprimento, a partir da inserção do tronco. Ao iniciar a brotação nos ramos primários, foram escolhidos dois brotos bem localizados e vigorosos que constituíram os ramos secundários (braços), e a planta com seis ramos produtivos foi submetida ao desponte.

No segundo ciclo (2001/2002), todas as plantas com desponte foram podadas a $5 \mathrm{~cm}$, permanecendo apenas uma brotação por ramo, constituindo seis ramos. As plantas sem desponte foram podadas a $15 \mathrm{~cm}$, restando-se, depois da brotação, dois brotos por ramo, perfazendo um total de 12 ramos.

A colheita dos frutos foi realizada quando eles se apresentavam verdes, inchados, com coloração interna do sicônio branca, com ostíolo fechado. Em cada colheita, determinou-se a produção média de frutos na parcela. Os frutos, depois de colhidos, foram lavados em água e, posteriormente, congelados para análises químicas. A massa do material verde de poda foi calculada por meio de pesagem a campo dos ramos retirados das plantas, depois de cada época de poda.

Foram marcados dois ramos por planta nas parcelas, com arame de alumínio, e calculou-se a média do comprimento total dos ramos, antes da poda de frutificação. Nas plantas com desponte, efetuou-se a soma de todas as ramificações que saíram dos braços.

A análise química dos frutos foi realizada no primeiro ciclo agrícola (2000/2001). Os frutos colhidos possuíam diâmetro médio de 33,37 mm, comprimento médio de $38,30 \mathrm{~mm}$ e peso médio dos frutos de $20 \mathrm{~g}$. Em cada colheita, foram retiradas amostras de 20 frutos por parcela, imediatamente congeladas e estocadas a $-25^{\circ} \mathrm{C}$, para proceder-se à análise de $\mathrm{pH}$, acidez total titulável, sólidos solúveis totais, açúcares totais, açúcares redutores e não-redutores e amido. Os frutos foram coletados, em todos os ramos produtivos, nas posições superior, inferior, externa e interna do ramo e, em seguida, foi retirada uma única amostra, em torno de $150 \mathrm{~g}$ de fruto triturado (triturador master) por tratamento, para realização das análises.

$\mathrm{O} \mathrm{pH}$ foi medido por meio de potenciômetro com eletrodo de vidro e a acidez total titulável (ATT), pela titulação com $\mathrm{NaOH}$ 0,1N; os resultados foram expressos em porcentagem de ácido cítrico (Association of Official
Analytical Chemists, 1992). O teor de sólidos solúveis totais (SST) foi avaliado por meio de um refratômetro digital, com compensação automática de temperatura, conforme a metodologia da (Association of Official Analytical Chemists, 1992). O conteúdo de SST foi expresso em ${ }^{\circ}$ Brix, com precisão de $0,1^{\circ}$ Brix, e corrigido para a temperatura de $25^{\circ} \mathrm{C}$. Os açúcares totais, redutores e não-redutores foram determinados a partir de $2 \mathrm{~g}$ de amostra triturada, em álcool etílico $80 \%$, e dosados pelo método descrito por Somogyi, adaptado por Nelson (1944).

A determinação de amido foi realizada a partir do resíduo, livre de açúcares. A amostra foi retirada do papel-filtro com $80 \mathrm{~mL}$ de água destilada, sendo transferida para erlenmeyer de $250 \mathrm{~mL}$. Colocou-se uma pitada de carbonato de cálcio e três gotas de $\mathrm{NaOH} 10 \%$, levando-se, por uma hora, à autoclave para se realizar a hidrólise básica. Retirou-se da autoclave e adicionaram-se $2,5 \mathrm{~mL}$ de $\mathrm{HCl}$ por béquer, permanecendo por 12 horas em repouso. No dia seguinte, foi realizada a neutralização a pH $7 \mathrm{com} \mathrm{NaOH}$. Em seguida, completou-se o volume para $100 \mathrm{~mL}$ em balão volumétrico, e obteve-se o extrato para determinação do amido pelo método de Somogyi, modificado por Nelson (1944).

\section{Resultados e Discussão}

Nos dois ciclos agrícolas, apenas a época de poda determinou diferenças significativas na produtividade da figueira (Tabela 1), não tendo sido verificado efeito do sistema de condução e nem interação entre os fatores. Os dados de produtividade relativos ao ciclo agrícola 2001/2002 demonstram níveis de produção superiores a $2.500 \mathrm{~kg} \mathrm{ha}^{-1}$ de figos verdes para indústria, que é a produção da figueira cultivar Roxo de Valinhos, no segundo ano de produção, no sul de Minas Gerais (Ramalho Sobrinho \& Geraldo, 1997). Observou-se também crescimento de produtividade entre o primeiro

Tabela 1. Produtividade $\left(\mathrm{kg} \mathrm{ha}^{-1}\right)$ de frutos da figueira (Ficus carica L.) sob diferentes épocas de poda ${ }^{(1)}$.

\begin{tabular}{lcc}
\hline Épocas de poda & $2000 / 2001$ & $2001 / 2002$ \\
\hline Março & $2.383 \mathrm{a}$ & $2.666 \mathrm{ab}$ \\
Junho & $1.677 \mathrm{ab}$ & $3.314 \mathrm{a}$ \\
Setembro & $976 \mathrm{~b}$ & $2.799 \mathrm{ab}$ \\
Dezembro & $1.234 \mathrm{~b}$ & $1.924 \mathrm{~b}$ \\
\hline
\end{tabular}

(1)Médias seguidas por mesma letra nas colunas não diferem entre si pelo teste de Tukey a 5\% de probabilidade. 
e o segundo ciclo, que continua aumentando no terceiro e quarto, estabilizando a partir do quinto ciclo, com produções da ordem de 12 a $15 \mathrm{Mg} \mathrm{ha}^{-1}$.

Conforme a Tabela 2, no ciclo agrícola 2000/2001, observaram-se diferenças significativas entre as épocas de poda, tendo as plantas podadas em março apresentado maiores valores de produção que as plantas podadas em setembro e dezembro, não diferindo estatisticamente das plantas podadas em junho. Plantas podadas no ciclo 2001/2002 também revelaram diferenças significativas entre as épocas de poda: as podadas em junho só diferiram estatisticamente das podadas em dezembro, não diferindo em relação a setembro e março. Esses resultados estão de acordo com Santos et al. (2001), que alcançaram bons níveis de produção da figueira Roxo de Valinhos, com poda em março e julho, na região de Selvíria, MS. Segundo esses autores, a poda em março propicia produção na entressafra da cultura (junho a novembro), alcançando melhores preços e menores custos de produção. Já Maraschin et al. (1992) e Norberto et al. (2001) citam que a poda antecipada, em regiões frias, reduz a produção em videira e figueira, respectivamente. Segundo Santos et al. (2001), é preferível que a poda da figueira seja realizada em março do que em agosto, pois, além de apresentar maior produtividade, cerca de $40 \%$ da produção podem ser obtidos fora de época da safra e conseguir maiores preços.

A poda precoce, realizada em março, revelou níveis superiores de produção em relação às podas mais tardias (dezembro), uma vez que as temperaturas amenas de inverno propiciaram desenvolvimento adequado das plantas. Valores mais baixos de produção das plantas podadas em dezembro podem ser explicados, uma vez que as plantas já haviam brotado ao serem podadas, eliminando grande quantidade de reservas já mobilizadas nesses brotos. Problema semelhante pode ocorrer em videiras, segundo Pujol (1972) e Hidalgo (1985).

No segundo ciclo agrícola, a produção das plantas podadas em setembro não diferiu estatisticamente das podadas em março (Tabela 2). Ao contrário, Rigitano (1964) relata que plantas podadas em setembro, em regiões mais frias, apresentaram produções mais baixas. Sob essas condições, as plantas passam por um rigoroso frio hibernal, brotando com muita intensidade na primavera e, se a planta for podada depois, perde-se muito as reservas. No entanto, valores mais baixos de produção podem ser compensados por preços maiores alcançados pelo produtor.

Pereira (1981) relata que a poda de frutificação na região de Valinhos é realizada de junho a agosto e a colheita de figos, para consumo como fruta fresca, estende-se de novembro a março.

Quanto ao peso de material verde de poda, nos ciclos agrícolas 2000/2001 e 2001/2002, não houve interação significativa entre os fatores época de poda e sistema de condução. Conforme Tabela 2, as plantas podadas no ciclo 2000/2001 revelaram diferenças significativas entre as épocas de poda, tendo as plantas podadas em março apresentado maiores pesos de material verde de poda em relação à poda em setembro, não diferindo em relação a dezembro e junho.

Walker et al. (1989), McCarthy \& Cirami (1990) e Southey \& Tooste (1991), estudando porta-enxertos diferentes de videira, verificaram que a produção de frutos apresenta correlação positiva com o peso do material podado. Neste trabalho, épocas com maior peso do material de poda tenderam a induzir maiores produções de frutos, o que pode ser explicado pelo fato de a figueira Roxo de Valinhos produzir um fruto por nó. Portanto, maior crescimento deve favorecer uma maior produção. Já Southey \& Fouché (1990) e Terra et al. (1990), avaliando porta-enxertos de videira, observaram que baixo peso do material de poda da copa pode propiciar uma produção relativamente alta e que o alto peso do material de poda pode ser responsável pelas baixas produções de frutos, devido a um desequilíbrio na relação carboidrato/nitrogênio.

Tabela 2. Produção (P), massa do material verde de poda (MMVP) e crescimento total de ramos (CTR) da figueira (Ficus carica L.), em diferentes épocas de poda, durante os anos agrícolas 2000/2001 e 2001/2002(1).

\begin{tabular}{|c|c|c|c|c|c|c|}
\hline \multirow[t]{2}{*}{ Épocas de poda } & \multicolumn{2}{|c|}{$\mathrm{P}\left(\mathrm{kg}\right.$ planta $\left.^{-1}\right)$} & \multicolumn{2}{|c|}{ MMVP $\left(\right.$ kg planta $\left.^{-1}\right)$} & \multicolumn{2}{|c|}{ CTR (m) } \\
\hline & $2000 / 2001$ & $2001 / 2002$ & $2000 / 2001$ & $2001 / 2002$ & $2000 / 2001$ & $2001 / 2002$ \\
\hline Março & $0,894 \mathrm{a}$ & $1,001 \mathrm{ab}$ & $1,837 \mathrm{a}$ & $1,939 a$ & $1,894 \mathrm{a}$ & $1,626 a b$ \\
\hline Junho & $0,629 \mathrm{ab}$ & $1,243 a$ & $1,540 \mathrm{ab}$ & $2,186 a$ & $1,860 \mathrm{a}$ & $1,869 \mathrm{a}$ \\
\hline Setembro & $0,366 \mathrm{~b}$ & $1,052 \mathrm{ab}$ & $1,229 b$ & $1,957 \mathrm{a}$ & $1,582 \mathrm{~b}$ & $1,672 \mathrm{ab}$ \\
\hline Dezembro & $0,463 \mathrm{~b}$ & $0,722 \mathrm{~b}$ & $1,371 \mathrm{ab}$ & $1,935 \mathrm{a}$ & $1,441 b$ & $1,397 b$ \\
\hline
\end{tabular}

(1)Médias seguidas por mesma letra nas colunas não diferem entre si pelo teste de Tukey a 5\% de probabilidade. 
As épocas de poda e o sistema de condução afetaram isoladamente o crescimento total dos ramos em ambos os ciclos agrícolas. No ciclo de poda 2000/2001, plantas podadas em março e junho apresentaram maior crescimento total dos ramos em relação a setembro e dezembro (Tabela 2). Em relação às plantas podadas no ciclo 2001/2002, as podadas em junho apresentaram maior crescimento total de ramos em comparação à poda de dezembro, não diferindo em relação a setembro e março.

Quanto ao sistema de condução, em ambos os ciclos agrícolas, não houve diferença estatística de produção entre o sistema com desponte e sem desponte (Tabela 3). Este fato vem indicar a possibilidade de utilização dos dois sistemas de condução, dependendo de cada situação. O sistema de condução sem desponte pode redundar em menores gastos com mão-de-obra nas operações de condução da planta. Porém, o sistema com desponte uniformiza o tamanho dos frutos abaixo da região despontada, uniformizando a colheita, possibilitando planejamento da colheita e economia na aplicação de produtos cúpricos. Essa economia ocorre pelo fato de todos os frutos serem colhidos ao mesmo tempo, ocorrendo menor número de aplicações de produtos no combate à ferrugem.

As plantas sem desponte apresentaram maior peso médio do material verde de poda. No ciclo 2001/2002, as plantas sem desponte apresentaram-se superiores às com desponte, demonstrando maior peso do material de poda (Tabela 3).

Em ambos os ciclos agrícolas, o sistema de condução com desponte demonstrou maiores valores de crescimento total dos ramos em relação ao sem desponte
(Tabela 3). Esses resultados vêm confirmar o efeito das épocas de poda no maior crescimento total dos ramos, ou seja, maior vigor, induzindo a maiores produções, desde que se tenha um equilíbrio adequado na relação carbono/nitrogênio, obtido por meio de podas corretas. Além disso, durante os dois ciclos produtivos, plantas despontadas apresentaram maior crescimento total de ramos e níveis similares de produção. Segundo Pinheiro (1979), o crescimento dos ramos em comprimento diminui com o aumento do número de ramos. Isso foi confirmado neste trabalho, em que houve maior crescimento final de ramos das plantas com desponte (seis ramos por planta), as quais apresentaram menor número de ramos no momento da poda em relação às plantas sem desponte (12 ramos por planta), no segundo ciclo agrícola.

Valores de crescimento total de ramos, nos dois ciclos de produção, foram bem superiores aos encontrados por Norberto et al. (2001). Segundo esses autores, o maior valor de comprimento total de ramos foi de $89,17 \mathrm{~cm}$ para a poda realizada em 15/7, sob condições de irrigação, no sistema com desponte. $\mathrm{O}$ maior crescimento total de ramos em regiões mais quentes, onde o inverno é mais ameno, como Salinas, MG, pode ser explicado pelas temperaturas mais elevadas que promovem a redução dos inibidores e favorecem os promotores de crescimento, elevando a atividade respiratória (Gardea et al., 1994).

Os dados de qualidade de frutos são referentes ao ciclo agrícola 2000/2001. Não houve interação significativa entre os fatores época de poda e sistemas de condução. Os fatores épocas de poda (Tabela 4) e sistemas de condução (Tabela 5) não influenciaram estatisticamente as variáveis sólidos solúveis totais, $\mathrm{pH}$,

Tabela 3. Produção (P), massa do material verde de poda (MMVP) e crescimento total de ramos (CTR) da figueira (Ficus carica L.), em diferentes sistemas de condução, durante os anos agrícolas 2000/2001 e 2001/2002(1).

\begin{tabular}{|c|c|c|c|c|c|c|}
\hline \multirow[t]{2}{*}{ Sistema de condução } & \multicolumn{2}{|c|}{$\mathrm{P}\left(\mathrm{kg}\right.$ planta $\left.^{-1}\right)$} & \multicolumn{2}{|c|}{ MMVP (kg planta $\left.{ }^{-1}\right)$} & \multicolumn{2}{|c|}{ CTR (m) } \\
\hline & $2000 / 2001$ & $2001 / 2002$ & $2000 / 2001$ & $2001 / 2002$ & $2000 / 2001$ & $2001 / 2002$ \\
\hline Com desponte & $0,516 a$ & $0,992 \mathrm{a}$ & $1,344 b$ & $1,757 b$ & $1,987 \mathrm{a}$ & $1,879 \mathrm{a}$ \\
\hline Sem desponte & $0,659 a$ & $1,017 \mathrm{a}$ & $1,645 \mathrm{a}$ & $2,252 \mathrm{a}$ & $1,404 b$ & $1,403 b$ \\
\hline
\end{tabular}

(1)Médias seguidas por mesma letra nas colunas não diferem entre si pelo teste de Tukey a 5\% de probabilidade.

Tabela 4. Qualidade de frutos de figueira (Ficus carica L.), expressa pelas características teor de sólidos solúveis totais (SST), pH, acidez total titulável (ATT), açúcares totais, glicose, sacarose e amido em diferentes épocas de poda ${ }^{(1)}$.

\begin{tabular}{|c|c|c|c|c|c|c|c|}
\hline Épocas de poda & SST $\left({ }^{\circ}\right.$ Brix $)$ & $\mathrm{pH}$ & ATT & $\begin{array}{c}\text { Açúcares } \\
\text { totais }\left(\mathrm{g} 100 \mathrm{~g}^{-1}\right)\end{array}$ & $\begin{array}{c}\text { Glicose } \\
\left(\mathrm{g} 100 \mathrm{~g}^{-1}\right)\end{array}$ & $\begin{array}{c}\text { Sacarose } \\
\left({\left.\mathrm{g} 100 \mathrm{~g}^{-1}\right)}\right.\end{array}$ & $\begin{array}{c}\text { Amido } \\
\left({\left.\mathrm{g} 100 \mathrm{~g}^{-1}\right)}^{-}\right.\end{array}$ \\
\hline Junho & $5,50 \mathrm{a}$ & $5,61 \mathrm{a}$ & $0,208 \mathrm{a}$ & $4,415 a$ & $3,340 \mathrm{a}$ & $1,023 a$ & $0,843 a$ \\
\hline Setembro & $5,69 \mathrm{a}$ & $5,61 \mathrm{a}$ & $0,253 \mathrm{a}$ & $4,404 a$ & $3,398 \mathrm{a}$ & $0,954 \mathrm{a}$ & $0,797 \mathrm{a}$ \\
\hline Dezembro & $5,81 \mathrm{a}$ & $5,63 \mathrm{a}$ & $0,208 \mathrm{a}$ & $4,130 \mathrm{a}$ & $3,226 a$ & $0,858 \mathrm{a}$ & $0,904 a$ \\
\hline Março & $5,53 \mathrm{a}$ & $5,67 \mathrm{a}$ & $0,234 \mathrm{a}$ & $4,417 \mathrm{a}$ & $3,317 \mathrm{a}$ & $1,051 \mathrm{a}$ & $0,777 \mathrm{a}$ \\
\hline
\end{tabular}

${ }^{(1)}$ Médias seguidas por mesma letra nas colunas não diferem entre si pelo teste de Tukey a 5\% de probabilidade. 
Tabela 5. Qualidade de frutos de figueira (Ficus carica L.), expressa pelas características teor de sólidos solúveis totais (SST), pH, acidez total titulável (ATT), açúcares totais, glicose, sacarose e amido em diferentes sistemas de condução(1).

\begin{tabular}{|c|c|c|c|c|c|c|c|}
\hline Sistema de condução & SST $\left({ }^{\circ}\right.$ Brix $)$ & $\mathrm{pH}$ & ATT & $\begin{array}{l}\text { Açúcares totais } \\
\left({\left.\mathrm{g} 100 \mathrm{~g}^{-1}\right)}\right.\end{array}$ & $\begin{array}{c}\text { Glicose } \\
\left({\left.\mathrm{g} 100 \mathrm{~g}^{-1}\right)}\right.\end{array}$ & $\begin{array}{c}\text { Sacarose } \\
\left({\left.\mathrm{g} 100 \mathrm{~g}^{-1}\right)}\right.\end{array}$ & $\begin{array}{c}\text { Amido } \\
\left({\left.\mathrm{g} 100 \mathrm{~g}^{-1}\right)}\right.\end{array}$ \\
\hline Com desponte & $5,58 \mathrm{a}$ & $5,67 \mathrm{a}$ & $0,220 \mathrm{a}$ & $4,329 a$ & $3,302 \mathrm{a}$ & $0,968 \mathrm{a}$ & $0,786 a$ \\
\hline Sem desponte & $5,68 \mathrm{a}$ & $5,59 \mathrm{a}$ & $0,231 \mathrm{a}$ & $4,354 \mathrm{a}$ & $3,308 \mathrm{a}$ & $0,974 \mathrm{a}$ & $0,874 \mathrm{a}$ \\
\hline
\end{tabular}

${ }^{(1)}$ Médias seguidas por mesma letra nas colunas não diferem entre si pelo teste de Tukey a 5\% de probabilidade.

acidez total titulável, açúcares totais, redutores e nãoredutores e amido.

Stino \& El-Fakharani (1995) relatam que a qualidade de frutos verdes de figueira cv. Conadria não foi afetada pelo sistema de poda com desponte depois da emissão de seis folhas e no sistema sem desponte dos ramos, concordando com os dados encontrados neste trabalho em relação ao sistema de condução. Chaudhari \& Desai (1994) verificaram efeito do sistema de poda na qualidade dos frutos verdes para a indústria, em sistema de poda severa $(30-45 \mathrm{~cm})$, em relação à poda leve $(5-10 \mathrm{~cm}$ na parte apical do ramo), de plantas de figueira cv. Poona, com quatro anos de idade.

Hernandes et al. (1994) não observaram diferenças significativas no teor de graus Brix dos frutos maduros de figueira Roxo de Valinhos em diferentes períodos de colheita. Os autores citam que a queda de folhas pode influenciar a queda no teor de açúcares. Já Condict (1947) cita que a intensidade de chuva, a incidência de ferrugem e a maior queda de folhas podem influenciar a qualidade dos frutos, em função de menor área foliar, menor fotossíntese, menor fluxo de fotoassimilados e conseqüente estresse. Os valores de SST podem variar de acordo com a cultivar, com as condições edafoclimáticas e com a época de colheita (Carvalho et al., 2001).

Pequenas variações de $\mathrm{pH}$ podem ser atribuídas ao efeito tamponante ocasionado pela presença simultânea de ácidos orgânicos e de seus sais, o que faz com que alterações na ATT não afetem significativamente os valores de $\mathrm{pH}$.

Em mangas, à medida que o fruto amadurece, as enzimas amilolíticas aumentam a sua atividade, havendo maior hidrólise de amido (Fuchs et al., 1980). Os níveis de amido encontrados, além de não diferirem estatisticamente para os fatores época de poda e sistemas de condução, apresentaram baixos teores (0,77 a 0,90 g $100 \mathrm{~g}^{-1}$ de fruto). Yoshioka (1995) e Tsantili (1990) também detectaram baixos níveis de amido em figo em todos os estádios de desenvolvimento do fruto.
A qualidade de frutos pode ser afetada por diferentes fatores que, em conjunto, possibilitarão a produção de frutos que atendam aos anseios do consumidor, que a cada dia está mais exigente. Entre esses fatores podese citar o clima (temperatura e umidade), práticas culturais, irrigação e fertilidade do solo (Aksoy et al., 1994).

$\mathrm{O}$ fato de não se ter encontrado diferenças significativas nas variáveis relativas à qualidade dos frutos, tanto em diferentes épocas de poda quanto em diferentes sistemas de condução, pode levar à determinação de uma única tecnologia de fabricação do doce de figo verde em calda e barra. Quantidades adicionadas de açúcar e ácido no processo de fabricação podem ser as mesmas em diferentes épocas de poda e sistemas de condução.

\section{Conclusões}

1. Plantas podadas em março apresentam maior produção em relação às podadas em dezembro, e propiciam uma produção na entressafra da cultura (junho a novembro).

2. Podem ser utilizados sistemas de condução sem desponte e com desponte na produção de figos verdes.

3. Mudança na época de poda e de sistema de condução não afeta a qualidade dos frutos verdes de figueira produzidos no norte de Minas Gerais.

\section{Referências}

ABRAHÃO, E.; ANTUNES, L.E.C.; SILVA, V.J.S. da. Poda e condução da figueira. Informe Agropecuário, v.18, p.6-13, 1997.

AKSOY, U.; ANAC, D.; SASS, P. Factors affeting quality of fresh and dried fig fruits. Acta Horticulturae, v.368, p.763766, 1994.

ALBUQUerque, J.A.S. de; ALBUQUERQUE, T.C.S. de. Comportamento da figueira (Ficus carica $L$.) cultivar roxo de valinhos no vale do São Francisco. Petrolina: Embrapa-CPATSA, 1981. 19p. (Boletim de pesquisa, 7).

ALMEIDA, M.M. de; SILVEIRA, E.T. da. Tratos culturais na cultura da figueira no Sudoeste de Minas Gerais. Informe Agropecuário, v.18, p.27-33, 1997. 
ASSOCIATION OF OFFICIAL ANALYTICAL CHEMISTS. Official methods of analysis of the Association of Official Analytical Chemistry. $12^{\text {th }}$ ed. Washington, 1992. 1094p.

CARVALHO, H.A. de; CHITARRA, M.I.F.; CHITARRA, A.B.; CARVALHO, H.S. de. Efeito da atmosfera modificada sobre componentes da parede celular da goiaba. Ciência eAgrotecnologia, v.25, p.605-615, 2001.

CHALFUN, N.N.J.; HOFFMANN, A.; PASQUAL, M. Frutíferas de clima temperado. Lavras: Ufla/Faepe, 1998. v.7, 304p.

CHAUDHARI, S.M.; DESAI, U.T. Effect of heading back on yield and physico-chemical characters of fig (Ficus carica L.) cv. Poona. Recent Horticulture, v.1, p.52-53, 1994.

CONDICT, I.J. The fig. Waltham: Chronica Botanica, 1947. 222p.

FUCHS, Y.; PESIS, E.; ZAUBERMAN, G. Changes in amylase activity, starch and sugars contents in mango fruit pulp. Scientia Horticulturae, v.13, p.155-160, 1980.

GARDEA, A.A.; MORENO, Y.M.; AZARENKO, A.N.; LOMBARD, P.B.; DALEY, L.S.; CRIDDLE, R.S. Changes in metabolic properties of grapebud during development. Journal of the American Society for Horticultural Science, v.119, p.756760, 1994.

HERNANDEZ, F.B.T.; SUZUKI, M.A.; BUZETTI, S.; CORREA, L.S. Resposta da figueira (Ficus carica L.) ao uso da irrigação e nitrogênio na região de Ilha Solteira. Scientia Agricola, v.51, p.99104, 1994.

HIDALGO, L. Poda de la vid. Madrid: Mundi Prensa, 1985. 222p.

MARASCHIN, M.; KOLLER, O.C.; SILVA, A.L. Efeito da época de poda e calcionamida na quebra de dormência e produtividade da videira cv. Niágara Branca, no Litoral catarinense. Pesquisa Agropecuária Brasileira, v.27, p.455-462, 1992.

McCARTHY, M.G.; CIRAMI, R.M. The effect of rootstocks on the performance of 'Chardonnay' from a nematode infested Barossa Valley vineyard. American Journal of Enology and Viticulture, v.41, p.126-130, 1990.

NELSON, N. A photometric adaptation of Somogyi method for determination of glicose. Journal of Biological Chemistry, v.135, p.136-175, 1944.

NOGUEIRA, A.M.M. Propagação da figueira (Ficus carica L.) através de estacas caulinares em casa de vegetação. 1995. 61p. Dissertação (Mestrado) - Universidade Federal de Lavras, Lavras.

NORBERTO, P.M.; CHALFUN, N.N.J.; PASQUAL, M. Efeitos da época de poda, cianamida hidrogenada e irrigação na produção antecipada de figos verdes. Pesquisa Agropecuária Brasileira, v.36, p.1363-1369, 2001.

PEDROTTI, E.L. Níveis de irrigação, crescimento das plantas e concentração de nutrientes nas folhas da figueira (Ficus carica L.) 'Roxo de Valinhos'. 1982. 88p. Dissertação
(Mestrado) - Universidade Federal do Rio Grande do Sul, Porto Alegre.

PEREIRA, F.M. Cultura da figueira. São Paulo: Livroceres, 1981. 73p. PINHEIRO, D. Influência do número de ramos de frutificação na produção de frutos verdes de figueira (Ficus carica $L$.) cv. São Pedro. 1979. 50p. Dissertação (Mestrado) - Universidade Federal de Pelotas, Pelotas.

PUJOL, J.N. Viticultura practica. Lerida: Dilagor, 1972. 370p.

RAMALHO SOBRINHO, R.S.; GERALDO, M.B. Aspectos econômicos da produção de figueira. Informe Agropecuário, v.18, p.24-26, 1997.

RESENDE, L.M. de A.; PAIVA, B.M. de; ALVARENGA, L.R. de. Considerações econômicas sobre citros, figo, maçã, pêssego e uva. Informe Agropecuário, v.17, p.56-63, 1994.

RIGITANO, O. A figueira cultivada no Estado de São Paulo. Campinas: Instituto Agronômico, 1964. 30p. (Boletim técnico, 146).

SANTOS, S.C.; TARSIANO, M.A.A.; CORRÊA, L.S. de. Análise econômica da figueira submetida a variações na época de poda e no número de ramos, na região de Selvíria-MS. Revista Brasileira de Fruticultura, v.23, p.64-68, 2001.

SOUTHEY, T.M.; FOUCHÉ, G.W. The performance of 'Chenin blanc' grafted on to different rootstock cultivars on a Dundee soil in the Montager district. South African Journal of Enology and Viticulture, v.11, p.50-54, 1990.

SOUTHEY, T.M.; TOOSTE, J.H. The effect of grapevine rootstock on the performance of Vitis vinifera L. (cv. Colombard) on a relatively saline soil. South African Journal of Enology and Viticulture, v.12, p.32-41, 1991.

STINO, R.G.; EL-FAKHARANI, E. Fruiting of conadria fig trees as affected by type of pruning and hydrogen cyanamide application. Egyptian Journal of Horticulture, v.22, p.193-211, 1995.

TERRA, M.M.; PIRES, E.J.P.; POMMER, C.V.; PASSOS, I.R.S.; MARTINS, F.P.; RIBEIRO, I.J.A. Comportamento de porta-enxertos para cultivar de uva de mesa 'Niágara rosada', em Jundiaí, SP. In: CONGRESSO BRASILEIRO DE FRUTICULTURA, 9., 1987, Campinas. Anais. Campinas: Sociedade Brasileira de Fruticultura, 1990. v.2, p.721-725.

TSANTILI, E. Changes during development of Tsapela fig fruits. Scientia Horticulturae, v.44, p.227-234, 1990.

WALKER, M.A.; WOLPERT, J.A.; VILAS, E.P.; GOHEEN, A.C.; LIDER, L.A. Resistant rootstocks may control fanleaf degeneration of grapevines. California Agriculture, v.43, p.13-14, 1989.

YOSHIOKA, K. Changes in sacharides and enzyme activities related to carbohydrate metabolism during growth and development of fig fruit (Ficus carica L.) on the tree. Journal of the Japanese Society for Food Science and Technology, v.42, p.219-224, 1995.

Recebido em 7 de junho de 2005 e aprovado em 3 de março de 2006 